\title{
Ensinar ciências por investigação: em quê estamos de acordo?
}

\author{
Danusa Munford e Maria Emília Caixeta de Castro e Lima
}

\section{Resumo}

Este trabalho objetiva apresentar e discutir fundamentos teóricos e filosóficos do ensino por investigação, procurando abordar algumas concepções dessa abordagem que são consideradas pouco apropriadas. Essa perspectiva de ensino vem orientando um curso de pós-graduação lato senso, ministrado pelo Centro de Ensino de Ciências e Matemática de Minas Gerais. Tomamos como pressupostos básicos as idéias de: 1) as explicações científicas surgem e se desenvolvem enquanto espaço de investigação orientada; 2) nos processos de formação de professores é preciso estabelecer um espaço permanente de investigação e trocas de vivências entre eles acerca da implementação dessa metodologia em seu trabalho. Os resultados até aqui encontrados dão conta de que houve uma ampliação significativa no entendimento dos professores sobre o que é ensino por investigação e quanto às suas aproximações e diferenças com um ensino experimental ou baseado em atividades de investigação simples e ritualística.

Palavras chaves: investigação, ensino de ciências e formação de professores

\begin{abstract}
In this work we intend to present and discuss the theoretical and philosophical foundations of inquiry in science teaching, addressing major misunderstandings about this approach. This perspective oriented a graduation program offered by the Centre for Science and Mathematics Teaching of Minas Gerais, Brazil (CECIMIG). The major assumptions underlying the program are: 1) scientific explanations emerge and develop as a space of guided investigation; 2) in the processes of teacher education it is essential to establish a space of investigation and of exchange of experiences in implementing this approach in the classroom. We perceived that teachers broadened their understandings about the differences and similarities between scientific inquiry and hands on science teaching or science teaching based on simple inquiry activities.
\end{abstract}

\section{Key-words: scientific inquiry, science teaching, teacher education}

\section{Introdução}

Desde o ano de 2005 o Centro de Ensino de Ciências e Matemática - CECIMIG -, órgão complementar da Faculdade de Educação da UFMG, está envolvido na produção e divulgação de conhecimento pedagógico sobre ensino de ciências por investigação.

Estamos especialmente interessados em caracterizar esse tipo de abordagem no ensino de ciências da natureza para a educação básica, identificar possibilidades de 
intervenção em sala de aula e avaliar os impactos dessas iniciativas no ensino e aprendizagem de ciências. Tal interesse é um desdobramento de outras produções que vêm ocorrendo no campo da formação de professores e da produção de material didático realizadas no âmbito da Faculdade de Educação da UFMG. Essas produções estão balizadas, entre outras coisas, pela crença de que aprender sobre ciências é tão importante quanto aprender ciências (Paula, 2004; Lima e Maués, 2006).

Visando a nos aproximar desse debate e continuar produzindo conhecimento sobre formação de professores de ciências da natureza, o Cecimig investiu em um projeto de ensino, pesquisa e extensão que engloba um curso de especialização lato senso, ofertado na modalidade semipresencial. Esse projeto atende, aproximadamente, 200 docentes de Física, Química e Biologia em dois Pólos: Belo Horizonte e Teófilo Otoni, além de um grupo de tutores e pesquisadores em ciências e em novas tecnologias da informação e comunicação.

Os professores cursistas são graduados na área de ciências da natureza ou comprovaram exercício de, no mínimo, 3 anos de docência na área. O curso faz parte de um projeto maior de pesquisa, ensino e extensão, tem duração prevista de dois anos e é financiado pela FINEP/MCT de acordo com o edital "Ciência de Todos". Os encontros de formação do grupo são semanais e aglutinam 4 formadores, 9 tutores, 2 bolsistas de graduação e 1 secretária do quadro técnico-administrativo. Temos como objetivos a instrumentalização para o trabalho de educação à distância (EAD); a articulação entre formação inicial e continuada de professores; o desenvolvimento de recursos didáticos para o ensino de ciências e a avaliação do projeto.

A fundamentação do ENCI reside no diagnóstico de que, de um modo geral, o ensino de ciências tem se realizado por meio de proposições científicas, apresentadas na forma de definições, leis e princípios e tomados como verdades de fato, sem maior problematização e sem que se promova um diálogo mais estreito entre teorias e evidências do mundo real. Em tal modelo de ensino, poucas são as oportunidades de se realizar investigações e de argumentar acerca dos temas e fenômenos em estudo. O resultado é que estudantes não aprendem conteúdos das Ciências e constroem representações inadequadas sobre a ciência como empreendimento cultural e social.

O curso em questão visa à qualificação e atualização dos docentes, com vistas à melhoria do ensino de ciências na Educação Básica por meio da superação dessa visão de 
ensino aqui, brevemente, caracterizada. O curso guarda já na sua origem dois pressupostos básicos: 1) o de que as explicações científicas surgem e se desenvolvem enquanto espaço de investigação orientada; 2) a necessidade de uma reflexão permanente e um de espaço de investigação e trocas de vivências entre os professores cursistas acerca da implementação dessa metodologia em seu trabalho, de modo a apoiar e sustentar mudanças nas escolas em que lecionam.

Coerentes com o objetivo de se ensinar ciências por investigação, o objeto de aprendizagem definido é o ensino por investigação. Várias atividades estão propostas para serem realizadas pelos professores e debatidas no fórum de discussão do curso.

Parte das reflexões geradas no âmbito do projeto ENCI foi recortada e segue apresentada neste artigo para fomentar o debate e suscitar nos colegas da educação em ciências o desejo de, também, expressarem seu modos de compreender e utilizar atividades investigativas no ensino.

\section{Ensino de Ciências por investigação}

Se o objetivo é inovação, falar em ensino de ciências por investigação é quase senso comum em países da América do Norte e Europa. No Brasil, entretanto, essa abordagem está menos "consagrada" e é relativamente pouco discutida. Mesmo assim, aqui, o interesse vem crescendo, sendo que pesquisadores e educadores voltam-se para a questão (e.g., Azevedo, 2004; Borges \& Rodrigues, 1998; Carvalho, Praia \& Vilches, 2005).

Neste artigo, para caracterizar nossa perspectiva acerca do ensino de ciências por investigação, pretendemos discutir a origem dessa abordagem no campo da educação em ciências, apresentar suas principais justificativas e contrapor algumas visões que hoje se consolidam no exterior. Acreditamos que uma visita à literatura de outros países, nos quais a discussão está mais sistematizada e direcionada, pode contribuir para a reflexão acerca do lugar dessa abordagem em nosso país e as formas que pode adquirir. Uma série de questionamentos pode emergir desse tipo de panorama. Até que ponto as iniciativas aqui adotadas estão organizadas em torno de um referencial teórico coerente? Dilemas e desafios que surgem em outros contextos foram considerados ao se elaborar as iniciativas nacionais no campo da pesquisa e no campo do ensino? Quais seriam algumas implicações para a formação de professores? Tais discussões são de grande importância em nosso país, na 
medida em que explicitam formas de pensar sobre o ensino de investigação, criando um espaço para o diálogo entre pesquisadores e educadores envolvidos com o ensino de ciências.

\section{Argumentos favoráveis à aproximação entre a Ciência da Escola e a Ciência dos Cientistas}

Quando falamos de Ensino de Ciências por Investigação, pretendemos sugerir imagens alternativas de aulas de ciências, diferentes daquelas que têm sido mais comuns nas escolas, dentre elas, o professor fazendo anotações no quadro, seguidas de explicações e os estudantes anotando e ouvindo-o dissertar sobre um determinado tópico de conteúdo.

Contudo, antes de entrarmos na caracterização do ensino por investigação, faz-se necessário indagar sobre os sentidos de se promover esse tipo de ensino: Por que mesmo é importante se ensinar ciências por meio de investigação? A tentativa de explicitarmos nossa posição sobre as contribuições do ensino por investigação na educação básica resulta da preocupação de se adotar determinadas perspectivas que estão em alta nas discussões acadêmicas. Esse tipo de orientação alternativa contribui para a aprendizagem de ciências? Em que sentido ela pode ajudar a solucionar problemas que enfrentamos em nossas salas de aula?

Apesar da grande diversidade de visões acerca do que é ensino por investigação, acreditamos que as diferentes propostas existentes podem ser melhor compreendidas a partir de uma mesma preocupação, qual seja, a de reconhecer que há um grande distanciamento entre a ciência ensinada nas escolas e a ciência praticada nas universidades, em laboratórios e outras instituições de pesquisa. Essa não é uma preocupação recente, embora assuma novas formas e esteja cada vez mais bem substanciada do ponto de vista teórico.

Aparentemente, muitas vezes, essas "duas ciências" - a escolar e a dos cientistas têm muito pouco em comum. Tal distanciamento pode ser facilmente identificado nos próprios conteúdos estudados. Contudo, alguns autores argumentam que mais preocupantes são as diferenças entre a representação das práticas "científicas" escolares e aquelas que são de fato práticas "científicas" dos cientistas. 
$\mathrm{Na}$ escola os conceitos são apresentados de forma abstrata e distanciados do contexto que lhe deram origem. Ocorre assim uma separação entre o que é aprendido do modo como esse conhecimento é aprendido e utilizado (Brown et al.,1989: 32). Os mesmos autores descrevem as atividades dos estudantes como centradas em uma forma de raciocínio estruturada a partir de leis, baseadas na manipulação símbolos para resolver problemas bem definidos, produzindo significados fixos e conceitos imutáveis. Um bom exemplo seria os problemas de genética ou equações em mecânica, bem como os cálculos envolvendo equilíbrio químico.

Esse quadro parece inconciliável com uma imagem do trabalho dos cientistas, considerados autênticos praticantes da ciência. Eles raciocinam com base em modelos causais, examinando situações para resolver problemas menos definidos, produzindo significados negociáveis e gerando uma compreensão socialmente construída (Brown et al.,1989, p.35).

De acordo com esse argumento, seria impossível compreender, de fato, um conceito científico como, por exemplo, seleção natural, de forma desvinculada da investigação de problemas autênticos como aqueles examinados por biólogos evolutivos, inclusive Darwin. Afinal, o conhecimento não seria apenas sensível ao contexto de aprendizagem ou origem, mas verdadeiramente dependente desse contexto.

Outros pesquisadores do campo de educação, ao definirem aprendizagem de ciências, deixam claro que aprender ciências implica necessariamente participar de algumas práticas dos cientistas, ou seja, um elemento central do contexto de produção do conhecimento científico. Driver et al. (1999), por exemplo, defendem que:

\footnotetext{
"aprender ciências não é uma questão de simplesmente ampliar o conhecimento dos jovens sobre os fenômenos - uma prática talvez mais apropriadamente denominada estudo da natureza - nem de desenvolver e organizar o raciocínio do senso comum dos jovens. Aprender ciências requer mais do que desafiar as idéias anteriores dos alunos mediante eventos discrepantes. Aprender ciências envolve a introdução das crianças e adolescentes a uma forma diferente de pensar sobre o mundo natural e de explicá-lo; tornando-se socializado, em maior ou menor grau, nas práticas da comunidade científica, com seus objetivos específicos, suas maneiras de ver o mundo e suas formas de dar suporte às assertivas do conhecimento" (Driver et al., 1999, p.36).
}

Sob essa perspectiva, seria inadequado dissociar a aprendizagem de conceitos científicos e as práticas da comunidade científica a partir das quais esses conceitos emergem. Como um todo, os posicionamentos aqui apresentados ilustram algumas das 
implicações que o distanciamento entre a ciência escolar e a ciência acadêmica poderia ter para a aprendizagem de ciências - em particular a contextualização dos conceitos científicos no campo de investigação acadêmica. As abordagens investigativas no ensino de ciências representariam um modo de trazer para a escola aspectos inerentes à prática dos cientistas.

\section{Tensões e Dilemas do Ensino de Ciências por Investigação: Examinando Diferenças entre a Ciência Escolar e a Ciência dos Cientistas}

Aproximar a ciência escolar da ciência acadêmica não é uma tarefa simples. Basta pensarmos sobre algumas diferenças essenciais entre esses dois espaços onde a "ciência" ocorre. Contudo, ao nos voltarmos para as tensões e contradições que podem emergir se essa aproximação for tomada como desejável, isso possibilitaria um melhor entendimento das diferentes tendências dentro do ensino por investigação bem como das polêmicas que emergem das variadas orientações.

É inegável que a ciência, nesses dois contextos, assume papéis e objetivos distintos. O principal objetivo da escola é promover a aprendizagem de um conhecimento científico já consolidado, enquanto, por outro lado, o principal objetivo da ciência acadêmica é produzir novos conhecimentos científicos.

Além disso, em espaços de prática da ciência dos cientistas, há o que poderíamos chamar de "recursos de ponta". Os cientistas contam com aportes tecnológicos e materiais em geral, mais avançados, como equipamentos sofisticados, instalações apropriadas, bibliotecas com acervo especializado etc. São mais qualificados e contam com uma equipe mais especializada nos assuntos que investigam, em termos de domínio de teorias e estudos na área de atuação bem como experiência com pesquisa científica. Nas escolas, ao contrário disso, contamos com uma infra-estrutura bem mais limitada para realizar investigações e trabalhamos com uma "equipe" pouco experiente nesse tipo de trabalho, além de apresentarem domínio limitado de teorias e estudos no campo.

Diante de tais diferenças, seria possível promover uma maior aproximação entre a ciência escolar e a dos cientistas? Até que ponto essa aproximação é possível sem caricaturar e banalizar a complexidade do trabalho dos cientistas em nossas salas de aula, ou sem que se promova uma visão estereotipada da ciência? Se examinarmos algumas 
iniciativas anteriores para promover essa aproximação bem como conhecermos diferentes posicionamentos de pesquisadores e educadores em relação à questão, ganharemos novos subsídios para construir essas respostas. Esse é um dos objetivos centrais deste artigo.

\section{A ciência escolar em busca de uma aproximação com a ciência dos cientistas}

Anteriormente, apresentamos argumentos que defendem a importância de aspectos como o processo e o contexto de produção de conhecimentos para a aprendizagem de ciências. Nesse momento, cabe-nos perguntar: "concretamente", quais seriam algumas propostas para implementar uma abordagem investigativa em salas de aula de ciências, química, física e biologia? Como as diferentes perspectivas lidam com o dilema das especificidades da ciência escolar e da ciência dos cientistas?

Neste texto, apresentaremos exemplos de diferentes abordagens ao ensino de ciências por investigação, contudo, não pretendemos abordar de forma exaustiva as múltiplas propostas que vêm sendo divulgadas. Iniciamos com uma breve discussão sobre algumas concepções equivocadas bastante comuns acerca de ensino de ciências por investigação. Em seguida, nos concentraremos em apresentar duas perspectivas desenvolvidas por autores ou grupos reconhecidos na comunidade de educadores de ciências e que, de certa forma, refletem dois posicionamentos em relação às questões da diferenças entre escola e academia ou laboratório científico. Uma das perspectivas, apresentada nos Parâmetros Curriculares Norte-Americanos de Ensino de Ciências, busca propor uma adequação de práticas dos cientistas levando em conta as características particulares do contexto escolar e o objetivo central de promover a aprendizagem de ciências (em seu sentido amplo). Essa proposta tem sido voltada para professores de todos os níveis de ensino nos Estados Unidos. Por outro lado, alguns autores têm avaliado as práticas escolares de ensino de ciências e enfatizado a necessidade de aproximá-las ao máximo do trabalho de cientistas em seus laboratórios. O artigo que serviu de base para representarmos essa perspectiva, "Epistemologically authentic inquiry in schools: A theoretical framework for evaluating inquiry tasks" de autoria de Chinn e Malhotra estava voltado para a comunidade acadêmica na área de Educação em Ciências, a qual está freqüentemente envolvida no desenvolvimento de materiais curriculares para o ensino de ciências. 


\section{Ensino de Ciências por Investigação: Que história é essa?}

Alguns autores afirmam que "não há nada de novo em aprender ciências através da investigação. Realizar observações, colocar questões e investigar sempre foram uma abordagem fundamental para compreender o mundo"1. Essa afirmação de Peter Dow, um educador norte-americano, parece consoante com uma visão comumente aceita de que a curiosidade é uma característica natural (e essencial) do ser humano e que, consequientemente, todas as atividades humanas deveriam ser guiadas pela curiosidade e pela investigação. Assim, nada seria mais "natural”, simples e espontâneo do que pensar em ensino de ciências como ensino de ciências por investigação.

O principal problema desse tipo de colocação é que ela torna triviais as iniciativas do ensino de ciências por meio da investigação. Pode parecer, por exemplo, que a preocupação com reverter a ênfase na transmissão de conceitos e teorias não tem um componente de novidade e que poderia ter surgido em qualquer contexto. Contudo, essa preocupação entre educadores das ciências da natureza deriva de uma profunda reflexão que tem relação direta com discussões que ocorreram nos campos da filosofia, sociologia e história da ciência bem como no campo dos estudos do currículo. Portanto, nada de natural, mas social e historicamente produzida.

Na década de 30, historiadores da ciência trouxeram à tona elementos importantes do processo de desenvolvimento do conhecimento científico. Esses estudos indicavam que “a visão de ciência enquanto um processo indutivo e lógico - um processo de partir de um fato empírico para o desenvolvimento de uma teoria científica - não era sustentada por estudos históricos” (Duschl, 1994, p. 445). Na década de 50, surgiram, entre os filósofos, autores que defendiam a idéia de que o conhecimento científico é afetado por perspectivas teóricas que o investigador possui e que são compartilhadas por uma comunidade de investigadores (Duschl, 1994, p. 445). Na década de 1960, essas idéias começaram a ter repercussões no campo da educação em ciências.

\footnotetext{
${ }^{1}$ Peter Dow (2005). Why inquiry? A historical and philosophical commentary. In: National Science Foundation Inquiry: Thoughts, Views, and Strategies for the K-5 Classroom, FOUNDATIONS: vol 2
} 
Constitui um marco no ensino de ciências por investigação uma série de trabalhos publicados pelo biólogo e educador Joseph $\mathrm{Schwab}^{2}$, sob influência de discussões na área de ciências humanas e sociais. Em 1960, em um estudo intitulado "O que os cientistas fazem?"3, Schwab propôs que o conhecimento científico estaria estruturado em duas categorias: o conhecimento científico substantivo e o conhecimento científico sintático. $\mathrm{O}$ primeiro representaria os significados compartilhados no grupo (conceitos, teorias, modelos, etc que buscam explicar fenômenos naturais). O conhecimento sintático envolveria as regras para se saber algo dentro das ciências naturais (procedimentos e práticas aceitas entre os cientistas como válidas para a construção de modelos). Em trabalhos posteriores, esse autor apresentou a idéia de um "ensino de ciências por investigação", baseado na proposição de que os currículos de ciência deveriam refletir aspectos do conhecimento sintático, isto é, dos processos e procedimentos para se chegar aos conhecimentos científicos. Nesse sentido, dois componentes são apontados como essenciais (Duschl, 1994, p. 449):

1. Os aprendizes têm de adquirir conhecimentos e experiências nas ciências naturais através de investigações adotando procedimentos similares àqueles que cientistas adotam e;

2. Os aprendizes têm de estar cientes de que o conhecimento a ser adquirido a partir das investigações está sujeito a mudanças.

\section{Ensino de Ciências por Investigação: concepções que julgamos equivocadas}

Ao longo do texto procuraremos questionar diretamente três concepções que consideramos equivocadas de ensino de ciências por investigação ${ }^{4}$ (NRC, 2002). Primeiramente, é muito comum pessoas acreditarem que o ensino de ciências por investigação envolve necessariamente atividades práticas ou experimentais ou que se

\footnotetext{
${ }^{2}$ Dentre eles cabe destacar "O ensino de ciências como investigação" ( Schwab, J.J., 1962, The teaching of science as enquiry. In: J.J. Schwab \& P.F. Brandwein (eds.) The teaching of science, Cambridge: Harvard University Press, p. 3-103.); O conceito e a estrutura de uma disciplina (Schwab, J.J., 1962, The concept and structure of a discipline. Educational Record, 43, 197-205); e "A estrutura das ciências da natureza" (Schwab, J.J., Schwab (1964), The structure of natural sciences. In: G.W. Ford \& L. Pugno (eds.), The structure of knowledge and the curriculum Chicago: Rand-McNally, p. 31-49.

${ }^{3}$ J.J. Schwab (1960), What do scientists do?, Behavioral Science, 5:1-27.

${ }^{4}$ Documentos com NSF (2005) e NRC (2000) apresentam essas concepções como sendo muito comuns, inclusive, entre professores da educação básica.
} 
restringe a elas. Contudo, se tomarmos como válidas as perspectivas apresentadas em nosso texto, podemos estar de acordo que uma atividade experimental, muitas vezes, não apresenta características essenciais da investigação, e que atividades que não são práticas podem ser até mais investigativas do que aquelas experimentais, dependendo da situação.

Em segundo lugar, é bastante difundida a noção de que o ensino de ciências por investigação tem de ser necessariamente um ensino envolvendo atividades bastante "abertas", nas quais os estudantes têm autonomia para escolher questões, determinar procedimentos para a investigação e decidir como analisar seus resultados. Veremos que muitos educadores discordam desse posicionamento e apresentam a possibilidade de múltiplas configurações com diferentes níveis de direcionamento por parte do(a) professor(a). Essa é uma proposta significativa, no sentido de que a organização das atividades investigativas em diferentes níveis de abertura ou controle possibilita a aprendizagem por meio de investigação entre alunos de diferentes faixas etárias e com diferentes perfis, inclusive aqueles com maiores dificuldades na área de ciências da vida e da natureza.

Finalmente, muitos acreditam que seria possível - e necessário - ensinar todo o conteúdo por meio de uma abordagem investigativa. A posição aqui defendida é de que alguns temas seriam mais apropriados para essa abordagem, enquanto outros teriam de ser trabalhados de outras formas. O ensino de ciências por investigação seria uma estratégia entre outras que o(a) professor(a) poderia selecionar ao procurar diversificar sua prática de forma inovadora.

\section{Ensino de Ciências por Investigação nos Parâmetros Curriculares Norte-Americanos ${ }^{5}$}

Os Parâmetros Curriculares Nacionais Norte-Americanos para o Ensino de Ciências (National Science Education Standards) foram publicados em 1996. A sua elaboração resultou de amplas discussões que agregaram associações de professores (como a Associação Nacional de Professores de Ciências, NSTA), de pesquisadores em educação em ciências (como a Associação Nacional de Pesquisa em Ensino de Ciências, NARST) e

5 As questões apresentadas nessa seção foram elaboradas a partir de uma leitura de dois documentos: Os Parâmetros Curriculares de Ensino de Ciências dos EUA (National Research Concil, 1996, The National Science Education Stardards) e um documento que fornece orientações para sua aplicação (National Research Council, 2000, Inquiry and the National Science Education Standards: A Guide for Teaching and Learning.) Ambos os documentos estão disponíveis no site www.nap.edu 
de pesquisadores das áreas de ciências da natureza (como a Associação Americana para o Progresso da Ciência, AAAS).

Um breve exame dos Parâmetros Curriculares Nacionais de Ciências dos Estados Unidos já revela a centralidade do ensino de ciências por investigação naquele país. $\mathrm{O}$ documento está organizado em oito parâmetros abrangentes. Há parâmetros para as áreas das ciências da natureza e suas intersecções (i.e., Conceitos Unificadores, Ciências Físicas, Ciências Biológicas, Ciências da Terra e do Espaço); parâmetros que buscam relacionar as ciências da natureza com seus aspectos sócio-culturais ou discussões oriundas das ciências humanas (i.e., Ciência e Tecnologia, Ciências sob a perspectiva pessoal e social, História e Natureza da Ciência); parâmetros especificamente voltados para o ensino de ciências por investigação. Esses últimos teriam como objetivo orientar o professor no sentido de desenvolver entre os estudantes de ciências: a) habilidades para fazer investigações científicas; b) uma melhor compreensão sobre a investigação científica.

Para os autores, fazer e compreender a investigação científica significa combinar conceitos e teorias científicas com processos, tais como observação, inferência, experimentação. Nesse caso, não basta fazer observações e levantar hipóteses sobre mudanças nas características de uma população de pássaros, nas características de um material ou no movimento de um objeto. Fazer ciências significa se apropriar de teorias do campo científico para investigar e explicar esses fenômenos, tais como a teoria da seleção natural, a teoria atômica ou as leis de Newton. Esse olhar "impregnado" de teorias científicas é parte essencial do "fazer científico" que muitas vezes não recebe a necessária articulação no ensino.

Além dessas considerações mais abrangentes sobre o ensino de ciências por investigação, os parâmetros curriculares norte-americanos e alguns documentos posteriores têm como preocupação central levar ao professor estratégias para trazer o ensino por investigação para as salas de aula. Nesse sentido, destaca-se o documento "Investigação e os Parâmetros Curriculares Nacionais de Ciências: Um Guia para Ensino e Aprendizagem" (Inquiry and the National Science Education Standards: A Guide for Teaching and Learning), elaborado em 2000. Esse trabalho propõe como essencial ao ensino de ciências por investigação que os aprendizes:

- engajem-se com perguntas de orientação científica; 
- dêem prioridade às evidências ao responder questões;

- formulem explicações a partir de evidências;

- avaliem suas explicações à luz de outras alternativas, em particular as que refletem o conhecimento científico;

- comuniquem e justifiquem explicações propostas.

Portanto, recomenda-se que, preferencialmente, o(a) professor(a) organize as situações de aprendizagem de forma que atividades relacionadas a cada um desses componentes componham a "investigação". Todavia, conforme a situação, nem todos os elementos terão de ser incorporados à seqüência de aulas investigativas. Naturalmente, dessa idéia resulta uma outra, a de que é necessário apresentar um elenco variado de aulas para trabalhar temas através da investigação. Conseqüentemente, seria impossível considerar que uma única aula por si só seja investigativa. Cabe ainda enfatizar que o nível de direcionamento e coordenação por parte do(a) professor(a) varia conforme as condições do contexto de ensino-aprendizagem, tais como disponibilidade de tempo, conceitos a serem trabalhados, características dos estudantes, relações dentro da turma e experiência do docente.

A Tabela 1 apresenta os diferentes níveis de organização das atividades para cada um dos elementos essenciais como propostos. Discutiremos essas possibilidades de organização, a seguir, quando abordaremos cada um dos elementos em maior detalhe.

Tabela 1: Variações nas atividades que contemplam elementos essenciais do ensino de ciências conforme maior ou menor direcionamento do professor (traduzido com adaptações a partir de NRC, 2000).

\begin{tabular}{|l|l|l|l|l|}
\hline \multicolumn{1}{|c|}{$\begin{array}{c}\text { Característica } \\
\text { Essencial }\end{array}$} & \multicolumn{3}{|c|}{ Variações } \\
\hline $\begin{array}{l}\text { 1. Aprendizes } \\
\text { engajam-se com } \\
\text { perguntas de } \\
\text { orientação } \\
\text { científica }\end{array}$ & $\begin{array}{l}\text { Aprendizes } \\
\text { propõem uma } \\
\text { questão }\end{array}$ & $\begin{array}{l}\text { Aprendizes } \\
\text { selecionam questão } \\
\text { entre questões } \\
\text { previamente } \\
\text { propostas, colocam } \\
\text { novas questões }\end{array}$ & $\begin{array}{l}\text { Aprendizes } \\
\text { delimitam melhor e } \\
\text { tornam mais clara } \\
\text { questão fornecida } \\
\text { pelo professor, ou } \\
\text { por materiais ou } \\
\text { outras fontes }\end{array}$ & $\begin{array}{l}\text { Aprendizes } \\
\text { engajam-se com } \\
\text { questão fornecida } \\
\text { pelo professor, } \\
\text { materiais ou outras } \\
\text { fontes }\end{array}$ \\
\hline $\begin{array}{l}\text { 2. Aprendizes dão } \\
\text { prioridade às } \\
\text { evidências ao } \\
\text { responderem às } \\
\text { questões }\end{array}$ & $\begin{array}{l}\text { Aprendizes } \\
\text { determinam quais } \\
\text { seriam as } \\
\text { evidências e } \\
\text { realizam coletas de } \\
\text { dados }\end{array}$ & $\begin{array}{l}\text { Aprendizes são } \\
\text { direcionados na } \\
\text { coleta de certos } \\
\text { dados }\end{array}$ & $\begin{array}{l}\text { Aprendizes } \\
\text { recebem dados e } \\
\text { têm de analisá-los }\end{array}$ & $\begin{array}{l}\text { Aprendizes } \\
\text { recebem dados e } \\
\text { instruções de como } \\
\text { analisá-los }\end{array}$ \\
\hline
\end{tabular}




\begin{tabular}{|c|c|c|c|c|}
\hline $\begin{array}{l}\text { 3. Aprendizes } \\
\text { formulam } \\
\text { explicações a partir } \\
\text { de evidências }\end{array}$ & $\begin{array}{l}\text { Aprendizes } \\
\text { formulam } \\
\text { explicações após } \\
\text { sumarizarem as } \\
\text { evidências }\end{array}$ & $\begin{array}{l}\text { Aprendizes são } \\
\text { guiados no } \\
\text { processo de } \\
\text { formulação de } \\
\text { explicações a partir } \\
\text { de evidências }\end{array}$ & $\begin{array}{l}\text { Aprendizes } \\
\text { recebem possíveis } \\
\text { formas de utilizar } \\
\text { evidências para } \\
\text { formular } \\
\text { explicações }\end{array}$ & $\begin{array}{l}\text { Aprendizes } \\
\text { recebem evidências }\end{array}$ \\
\hline $\begin{array}{l}\text { 4. Aprendizes } \\
\text { avaliam suas } \\
\text { explicações à luz } \\
\text { de explicações } \\
\text { alternativas e } \\
\text { conectam suas } \\
\text { explicações ao } \\
\text { conhecimento } \\
\text { científico }\end{array}$ & $\begin{array}{l}\text { Aprendizes } \\
\text { examinam } \\
\text { independentemente } \\
\text { outros recursos e } \\
\text { estabelecem as } \\
\text { relações com as } \\
\text { explicações }\end{array}$ & $\begin{array}{l}\text { Aprendizes são } \\
\text { direcionados para } \\
\text { áreas ou fontes de } \\
\text { conhecimento } \\
\text { científico }\end{array}$ & $\begin{array}{l}\text { Aprendizes são } \\
\text { informados acerca } \\
\text { de possíveis } \\
\text { conexões }\end{array}$ & \\
\hline $\begin{array}{l}\text { 5. Aprendizes } \\
\text { comunicam e } \\
\text { justificam } \\
\text { explicações }\end{array}$ & $\begin{array}{l}\text { Aprendizes } \\
\text { constroem } \\
\text { argumentos } \\
\text { razoáveis e lógicos } \\
\text { para comunicar } \\
\text { explicações }\end{array}$ & $\begin{array}{l}\text { Aprendizes são } \\
\text { treinados no } \\
\text { desenvolvimento } \\
\text { da comunicação }\end{array}$ & $\begin{array}{l}\text { Aprendizes } \\
\text { recebem diretrizes } \\
\text { para tornar sua } \\
\text { comunicação mais } \\
\text { precisa }\end{array}$ & $\begin{array}{l}\text { Aprendizes } \\
\text { recebem instruções } \\
\text { passo a passo e } \\
\text { procedimentos para } \\
\text { se comunicarem }\end{array}$ \\
\hline Meno & ---- Níve & mento do profess & $\begin{array}{l}\text { prendizes --------- } \\
\text { pu de material ----- }\end{array}$ & $\begin{array}{l}\text { Menos } \\
-- \text { Mais }\end{array}$ \\
\hline
\end{tabular}

Em atividades voltadas para que os aprendizes engajem-se com perguntas de orientação científica, um dos maiores desafios (para docentes e alunos) seria justamente compreender quais questões poderiam ser consideradas "questões científicas" pertinentes no contexto do ensino de ciências da natureza por investigação. Sob a perspectiva dos Parâmetros Curriculares Norte-Americanos essas questões: 1) são centradas em objetos, organismos e eventos do mundo natural, 2) estão relacionadas a conceitos científicos, 3) levam a investigações empíricas, à coleta e ao uso de dados para desenvolver explicações para fenômenos (p. 24). Além disso, os autores apontam que questões do tipo "como" são mais apropriadas do que questões do tipo "por que" (p. 24), pois estão centradas em caracterizar fenômenos naturais estabelecendo relações causais, mas sem desembocar numa perspectiva finalista do mundo.

Se pensarmos em perguntas que nós e nossos alunos já apresentamos em sala de aula sob essa perspectiva, provavelmente, grande parte delas não seria apropriada para uma aula de natureza investigativa. Portanto, é natural que, muitas vezes, o (a) professor (a) tenha que direcionar mais seus alunos na elaboração de questões para investigação, principalmente quando se depara com uma turma com pouca experiência com essa abordagem ou quando há maior limitação de tempo (Tabela 1). Nesse sentido, os alunos podem, inclusive, receber uma questão pronta para investigarem. No caso, ela seria 
previamente elaborada pelo professor ou obtida em materiais didáticos (coluna 5). Quando os alunos pertencem a faixas etárias mais avançadas, têm maior experiência com a aprendizagem de ciências por investigação ou em que há grande disponibilidade de tempo, sua autonomia para elaborar as questões a serem investigadas é maior (coluna 2).

O segundo aspecto levantado no documento do National Research Council (2000) refere-se à noção de fazer com que os aprendizes dêem prioridade às evidências ao responderem questões. Essa orientação reflete uma preocupação com o fato de que, freqüentemente, os argumentos construídos nas aulas de ciências para explicar fenômenos naturais estão centrados na autoridade do professor (ou seja, aceito porque "quem sabe" é que fala) ou na plausibilidade (é uma explicação "lógica" que faz sentido) ${ }^{6}$. O que se busca enfatizar é a necessidade de fornecer evidências empíricas que sustentem uma explicação científica, mesmo na ciência escolar. Haveria uma ênfase na utilização por parte dos alunos de evidências empíricas como base para suas explicações. Isso poderia envolver a coleta de dados acurados a partir de observação e tomada de medidas. Além disso, os aprendizes seriam desafiados a controlar condições ou a coletar dados em diferentes condições (p. 2526).

Novamente, cabe ressaltar que essas atividades podem ser estruturadas de formas diferentes (Tabela 1). Os alunos podem usar dados já coletados com maior ou com menor orientação do(a) professor(a) ou coletar seus dados em condições mais ou menos estruturadas. A combinação de diferentes estratégias, inclusive, ilustra de maneira apropriada como cientistas coletam e utilizam diferentes tipos de dados de formas variadas. Em algumas situações, por exemplo, cientistas coletam dados em laboratório adotando protocolos pré-estabelecidos bem estritos, em outras, vão a campo e fazem observações na natureza, ainda em outras, recorrem a bancos de dados coletados por outros cientistas para realizar complexas análises estatísticas. Idealmente, ao longo de sua educação formal os alunos deveriam vivenciar essas múltiplas abordagens.

De acordo com o terceiro elemento, seria essencial que os aprendizes de ciências elaborassem explicações a partir das evidências coletadas ou selecionadas. Assim, seria

\footnotetext{
${ }^{6}$ Veja: 1) Chinn, C. A. (1998). A critique of social constructivist explanations of knowledge change. In B. Guzzetti \& C. Hynd (Eds.), Perspectives on Conceptual Change: Multiple ways to understand knowing and learning in a complex world (pp. 77-115). Mahwah: L. Erlbaum Associates, Publishers. e 2) Sandoval, W. A., \& Reiser, B. J. (2004).Explanation-driven inquiry: integrating conceptual and epistemic scaffolds for scientific inquiry. Science Education, 88. 345-372.
} 
trabalhada a distinção entre evidência e explicação, estabelecendo-se relações baseadas em evidências na construção de um argumento. Tais explicações estão abertas à crítica e dependem do uso de vários processos cognitivos associados à ciência (classificação, análise, inferência, pensamento crítico). Além disso, dependendo do momento em que ocorrem, podem representar uma oportunidade importante para estudantes construírem novas idéias a partir dos seus conhecimentos iniciais (p. 26-27).

Sob essa perspectiva de ensino de ciências por investigação, é fundamental que aprendizes avaliem as explicações construídas à luz de explicações alternativas. Propor questões é um passo inicial importante nesse sentido: "As evidências de fato sustentam a minha explicação?" "A minha explicação responde ao problema?", "Outras explicações podem ser geradas a partir dessas evidências?". Além disso, deve-se criar um espaço para contrastar as próprias explicações com explicações de colegas e explicações científicas. Em seguida, criam-se condições para que as explicações sejam revisadas e reelaboradas (p. 27). Mais uma vez, cabe lembrar que as relações com o conhecimento científico consolidado podem ser estabelecidas por meio de diferentes tipos de atividades (Tabela 1), as quais, nesse caso, não são necessariamente excludentes. O professor pode introduzir, ele mesmo, conceitos e teorias cientificamente aceitas, ou os alunos podem explorar fontes disponíveis com diferentes níveis de autonomia.

Finalmente, um último aspecto do ensino de ciências por investigação está relacionado à idéia de que é importante os aprendizes comunicarem e justificarem suas explicações. Apresentar de alguma forma suas explicações exige que os estudantes articulem a questão investigada, os procedimentos adotados na coleta e análise de dados, as evidências obtidas e a revisão das explicações à luz de posições alternativas. Além disso, criam-se oportunidades para que os alunos tenham que elaborar suas próprias questões em relação a outros trabalhos e desenvolvam critérios para avaliar aquilo que os colegas produziram (p.27). Em suma, acredita-se que na medida em que o aluno vivencia todos esses aspectos essenciais, ele passa a ter um conhecimento mais apropriado acerca das práticas dos cientistas e dos processos de construção de teorias científicas. A própria aprendizagem dos conceitos científicos também é mais aprofundada e significativa, uma vez que esses conceitos e teorias são introduzidos em meio a elementos essenciais de seu contexto de produção. 


\section{Investigação científica autêntica: Uma perspectiva que parte das práticas dos cientistas para avaliar atividades escolares ${ }^{7}$}

Na seção anterior discutimos a perspectiva sobre ensino de ciências por investigação apresentada nos Parâmetros Curriculares Nacionais Norte Americanos, agora, discutiremos uma segunda perspectiva. Ela está voltada para avaliar até que ponto as atividades investigativas desenvolvidas na escola representam fielmente o tipo de raciocínio dos cientistas e as visões sobre o conhecimento produzido nesse contexto científico. Uma leitura desse posicionamento é que, a princípio, as práticas presentes na ciência dos cientistas deveriam ditar as características centrais do que fazemos na escola.

No artigo que serviu de referência para representar essa perspectiva, Clark Chinn e Betina Malhotra inicialmente comparam atividades de investigação simples encontradas em livros didáticos com situações de investigação autêntica, ou seja, descrições de casos históricos em que cientistas investigaram e construíram respostas para um problema científico. Na Tabela 2 apresentamos um exemplo de atividade de investigação simples e um de investigação autêntica disponibilizados por esses autores. Eles propõem que comparações devem ser realizadas considerando-se duas dimensões: aspectos cognitivos e aspectos epistemológicos.

Tabela 2: Dois dos exemplos fornecidos por Chinn \& Malhotra (2002).

\begin{tabular}{|l|l|}
\hline Atividade de Investigação Simples & $\begin{array}{l}\text { Experimento para alunos do que corresponderia ao } 3^{\circ} \text { ciclo do ensino } \\
\text { fundamental: "os estudantes fixam uma régua de um metro na extremidade de } \\
\text { uma mesa de modo que a régua fique para fora da mesa. Então, os estudantes } \\
\text { penduram pesos de diferentes tamanhos na régua. O propósito do experimento } \\
\text { é investigar o efeito do peso (a única variável dependente) na curvatura da } \\
\text { régua (a única variável dependente)". }\end{array}$ \\
\hline Estudo da fermentação por Buchner (1897): o cientista macerou células de \\
levedo com areia, água e solo, produzindo um líquido sem células intactas de \\
levedo. Em um caso, adicionou na mistura glicose (conhecida por fermentar na não Autêntica \\
presença de leveduras) e no outro, lactose (que não fermenta na presença de \\
levedos). A fermentação ocorreu apenas na mistura com glicose, demonstrando \\
que células intactas não são necessárias. Buchner propôs que a fermentação é \\
mediada por uma substância encontrada em leveduras que ele chamou de \\
"zimase". Além disso, sugeriu que quando células intactas realizam a \\
fermentação, as células secretam zimase de modo que a fermentação ocorre \\
fora das células de levedura, e não dentro delas.
\end{tabular}

7 As discussões desenvolvidas nessa seção derivam do artigo Chinn \& Malhotra, B.A. (2002). Epistemologically authentic inquiry in schools: A theoretical framework for evaluating inquiry tasks. $\underline{\text { Science }}$ Education 86:175-218 (Investigações epistemologicamente autênticas em escolas: Um referencial teórico para avaliar atividades investigativas) 
Os processos cognitivos envolvidos na investigação científica refletem as formas como se raciocina nesses contextos. Para caracterizar tais processos Chinn e Malhotra, (2002) identificam cinco tipos de processos cognitivos centrais a serem comparados:

- Gerar questões de pesquisa;

- Planejar as investigações;

- Realizar observações;

- Explicar resultados;

- Desenvolver teoria;

- Estudar outros relatos de pesquisa

As comparações indicam que há grandes diferenças entre o tipo raciocínio demandado de cientistas engajados em investigações autênticas e as formas de pensar que os alunos têm a oportunidade de vivenciar no ensino básico, engajados, no máximo, em investigações simples. Primeiramente, cientistas geram suas próprias questões de pesquisa, enquanto alunos do ensino básico participam de atividades em que as questões são fornecidas.

Em segundo lugar, ao planejarem seus estudos, cientistas selecionam e criam variáveis, trabalhando com muitas delas. Em atividades escolares, os alunos tendem a trabalhar com poucas variáveis, facilmente identificáveis e que são fornecidas pelo professor. Evidentemente, há importantes desdobramentos para todas as etapas da investigação quando trabalhamos com múltiplas variáveis. Além disso, os autores destacam que, por um lado, os procedimentos adotados na escola são bastante diretos e os alunos apenas seguem passos pré-estabelecidos. Por outro lado, na investigação autêntica, os procedimentos são complexos e sua elaboração envolve esforço significativo. Essa complexidade também está presente quando cientistas realizam observações. Nesse caso, eles têm uma grande preocupação com possíveis vieses de suas observações, procurando desenvolver metodologias que reduzam problemas dessa natureza. Infelizmente, em atividades investigativas simples pouco se discute a questão de diferenças de percepção e "erro" nas mensurações.

A construção de explicações a partir dos resultados em contextos mais autênticos foi examinada em relação a uma série de aspectos. Uma de suas características envolve transformar dados brutos em outros tipos de dados, por exemplo, por meio de análises 
estatísticas e construção de gráficos. Além disso, o raciocínio é extremamente indireto. Uma conseqüência seria que as variáveis medidas e manipuladas na investigação não são idênticas às variáveis teóricas de interesse. As primeiras são relacionadas às segundas por meio de uma cadeia indireta de referências (p. 185).

Em atividades simples de investigação há pequena preocupação em desenvolver teorias. Nesse caso, o foco está na observação direta de um fenômeno empírico. Em geral, o(a) professor(a) apresenta a teoria e os dados coletados servem mais como um exemplo para ser utilizado ao se explicar a teoria. Os alunos, de fato, não constroem explicações teóricas com base em evidências (p. 186). Além disso, destacam os autores, raramente os alunos têm de coordenar resultados de múltiplos estudos (por exemplo, atividades práticas diferentes) para construir suas explicações. Os cientistas desenvolvem estratégias interpretativas para coordenar resultados entre diversos estudos, inclusive nos casos em que seus resultados são aparentemente conflituosos (p. 186).

Finalmente, um aspecto bastante importante no trabalho de cientistas é o estudo de relatos de pesquisa de outros cientistas. Suas conclusões são baseadas no trabalho teórico e empírico de outros cientistas. Em contraste, pesquisas de outros cientistas praticamente não têm qualquer papel em investigações simples na escola. Em suma, as análises realizadas por Chinn e Malhotra explicitam grandes diferenças entre os processos cognitivos envolvidos no trabalho dos cientistas e aqueles envolvidos no trabalho de estudantes de ciências no contexto escolar.

Se há fortes indícios de que os alunos em nossas aulas estão "pensando" de modo tão distinto dos cientistas, o que se pode dizer sobre como a organização do ensinoaprendizagem na escola, com base em atividades de investigação simples, tem representado aspectos epistemológicos da ciência? Quando nos referimos à epistemologia, nos voltamos para crenças sobre o que é o conhecimento científico, sobre como esse conhecimento é produzido, estabelecido e validado, e sobre quando e como se transforma.

Para os autores, a epistemologia de atividades de investigação simples é tão distinta daquela de investigações autênticas, que as duas podem ser consideradas epistemologias opostas. Tais diferenças são identificadas a partir de uma comparação em relação a vários aspectos:

- O propósito da pesquisa; 
- A coordenação entre teoria e dados;

- A influência da teoria nos métodos;

- A natureza do raciocínio;

- A construção social do conhecimento.

Vamos nos ater a dois aspectos para discutirmos no presente artigo. Primeiramente, o de que um propósito central da pesquisa na "ciência real (...) é desenvolver e refinar modelos teóricos em resposta a evidências". Ao contrário, "o objetivo das atividades de investigação simples é apenas detectar regularidades facilmente observáveis" (p. 187). "Um outro aspecto da epistemologia da ciência autêntica é a construção do conhecimento científico através de processos sociais e instituições" (p. 190, grifo nosso). Chinn e Malhotra reconhecem que os trabalhos em grupo têm sido bastante freqüentes em nossas salas de aula, representando um importante aspecto da construção social do conhecimento algo análogo ao trabalho dos cientistas em equipes.

Porém, outros elementos importantes dessa construção social do conhecimento não aparecem no contexto escolar: o estudo de trabalhos anteriores, a adoção de procedimentos institucionalizados (por exemplo, a revisão de artigos por colegas antes da publicação), a identificação de "modelos" de métodos de pesquisa e de "padrões" de argumentos compartilhados dentro do campo. Em nossas salas de aula, por exemplo, raramente desenvolvemos discussões com o objetivo de tornar mais explícitas algumas normas de comunicação na ciência escolar, tais como quais seriam os componentes essenciais em uma explicação científica ou critérios aceitáveis para uma "boa" classificação etc.

Chinn e Malhotra deixam claras as possíveis repercussões de um trabalho que representa inadequadamente aspectos epistemológicos da ciência:

"Uma importante implicação de nossas análises é que atividades de investigação simples podem não apenas deixar de ajudar os alunos a aprender a raciocinar cientificamente; elas podem também favorecer uma epistemologia de acordo com a qual o raciocínio científico é visto como simples, certo, algorítmico, e focado em uma observação superficial. Pesquisadores têm constatado que muitos estudantes parecem possuir tais crenças acerca da ciência (...) nossas análises sugerem que atividades investigativas simples utilizadas nas escolas podem ser parcialmente responsáveis por promover essas crenças“ (Chinn e Malhotra , 2002, p. 190). 


\section{É possível desenvolver atividades investigativas mais autênticas em sala de aula?}

Chinn e Malhotra apresentam um quadro um tanto negativo das atividades escolares a partir de suas análises de atividades investigativas simples, ou seja, aquelas que os estudantes vivenciam predominantemente. Todavia, identificam atividades mais complexas desenvolvidas por pesquisadores do campo da educação em ciências - classificadas como Atividades Práticas, Experimentação Simulada em Computador, Atividades com Bancos de Dados, Atividades de Avaliação de Evidências, Elaboração Verbal de Desenho de Pesquisa. As propostas são avaliadas a partir das oportunidades que aprendizes têm de:

- Gerar as próprias questões;

- Selecionar variáveis;

-Desenvolver Controles (simples ou complexos);

-Fazer múltiplas observações;

- Observar ou avaliar variáveis "interferentes";

-Utilizar modelos análogos;

-Transformar observações (simples ou complexa);

- Considerar limitações metodológicas;

-Desenvolver teorias sobre mecanismos;

- Realizar vários estudos do mesmo tipo;

- Realizar vários estudos de diferentes tipos;

-Estudar relatos de pesquisa de especialistas.

As propostas analisadas ilustram melhor alguns desses aspectos e possuem limitações em relação a outros. Por um lado, em atividades práticas mais abertas, por exemplo, os estudantes podem discutir quais seriam as variáveis mais apropriadas, elaborar experimentos mais complexos, refletir sobre "erros" de medida. Contudo, Chinn e Malhotra argumentam que "é relativamente difícil para os estudantes conduzirem experimento em níveis teóricos profundos de análise", ou seja, esse tipo de atividade estaria mais centrada na investigação de fenômenos observáveis do que no estudo das teorias que explicam tais fenômenos (p. 206). Nesse caso, conceitos e teorias mais complexos e mais abstratos 
dificilmente poderiam ser explorados, principalmente se considerarmos os recursos disponíveis no contexto escolar para a realização de atividades práticas.

Por outro lado, atividades com bancos de dados possuem grande potencial para que os estudantes vivenciem aspectos da investigação autêntica na interpretação de dados e análise crítica das metodologias adotadas (e.g., considerar limitações metodológicas, desenvolver teorias sobre mecanismos, realizar vários estudos de diferentes tipos) (p. 207). Todavia, os estudantes não podem elaborar suas próprias investigações e coleta de dados, o que dificulta a vivência de vários aspectos da investigação autêntica (e.g., selecionar variáveis, desenvolver controles).

\section{Considerações Finais}

Como podemos nos apropriar das propostas e das críticas apresentadas nos trabalhos discutidos em nosso contexto escolar brasileiro? Em que sentido elas nos sensibilizam para os desafios que ainda temos de enfrentar ao tentar aproximar a ciência dos cientistas da ciência escolar? Essas são algumas das reflexões que pretendemos suscitar em nosso trabalho com professores em formação continuada. Nesse sentido, tem sido fundamental relacionar tais referenciais às experiências concretas dos cursistas envolvidos, trabalho que vem sendo desenvolvido por outros colegas da equipe do Cecimig. É preciso, ainda, fazer uma avaliação dos sentidos dessa nova perspectiva para na formação de professores e de suas possibilidades de promover mudanças em nossas salas de aula.

Contudo, cabe lembrar que para formadores de professores esse representa um grande desafio, uma vez que, mesmo no cenário internacional, alguns pesquisadores já chamam a atenção para as limitações das orientações e pesquisas acerca de como professores do ensino básico ensinam ciências através de investigação (Flick et al. 1997, Friedrichsen et al., 2006). Essa abordagem inovadora recebe destaque em diretrizes curriculares e materiais didáticos norte-americanos. Todavia, para aqueles que trabalham em sala de aula ainda há um longo caminho a percorrer. Permanecem questões de como planejar, ensinar e avaliar os alunos sob uma perspectiva investigativa (Keys e Kennedy, 1999).

Por fim, são múltiplas as perspectivas sobre o papel e o lugar do ensino de ciências por investigação na formação dos estudantes da educação básica. No âmbito do Projeto 
ENCI é relativamente consensual entre os coordenadores e os tutores a avaliação de que houve uma ampliação significativa no entendimento dos professores sobre o que é ensino por investigação e sobre suas aproximações e diferenças com um ensino experimental ou baseado em atividades de investigação simples e ritualística. Como objeto de aprendizagem, a discussão sobre ensino por investigação tem gerado nos participantes uma certeza de que é preciso promover um ensino mais interativo, dialógico e baseado em atividades capazes de persuadir os alunos a admitirem as explicações científicas para além dos discursos autoritários, prescritivos e dogmáticos. Assim, já terá sido válido o debate que temos fomentado durante o processo de formação no projeto.

\section{Referências Bibliográficas}

Azevedo M.C.P.S Ensino por Investigação: Problematizando as atividades em sala de aula. In: Carvalho, A.M.P. (org.), Ensino de Ciências: Unindo a Pesquisa e a Prática, p. São Paulo: Thomson, 2004.

BORGES, A. T.; RODRIGUES, B. A.; Aprendendo a planejar investigações. In: ENCONTRO DE PESQUISA EM ENSINO DE FÍSICA, IX, 2004, Jaboticatubas. Atas... Minas Gerais: SBF, 2004.

Brown, J. S., A. Collins, et al. (1989). "Situated cognition and the culture of learning." Educational Researcher 18: 32-42Chinn \& Malhotra, B.A. (2002). Epistemologically authentic inquiry in schools: A theoretical framework for evaluating inquiry tasks. Science Education 86:175-218.

Carvalho, A. M. P.; Praia, J.; Vilches, A (orgs), (2005). A necessária renovação do ensino de ciências. São Paulo: Cortez. 2005.

Chinn, C. A. (1998). A critique of social constructivist explanations of knowledge change. In B. Guzzetti \& C. Hynd (Eds.), Perspectives on Conceptual Change: Multiple ways to understand knowing and learning in a complex world (pp. 77-115). Mahwah: L. Erlbaum Associates, Publishers.

Chinn, C; Malhotra, B.A. (2002). Epistemologically authentic inquiry in schools: A theoretical framework for evaluating inquiry tasks. Science Education, 86:175-218.

Driver, R., H. Asoko, et al. (1999). "Construindo conhecimento científico na sala de aula." Revista Química Nova na Escola, 1(9). 31-40.

Duschl, R. A. (1994). Research on the history and philosophy of science. Handbook of research on science teaching and learning. D. Gabel. New York, MacMillan Publishing Company: p.443-465.

Flick, L. B., C. W. Keys, et al. (1997). Perspectives on Inquiry-Oriented Teaching Practice: Conflict and Clarification. Trabalho apresentado no Encontro anual da NARST, Oak Brook, IL, USA. 
Friedrichsen, P., D. Munford, et al. (2006). Brokering at Boundary: A Prospective Science Teacher Engages Students in Inquiry. Science Education 90(3): 522-543

Keys, C. W. and V. Kennedy (1999). Understanding inquiry science teaching in context: A case study of an elementary teacher. Journal of Science Teacher Education 10(4): 315-333.

Lima, M. E. C. C.; Maués, E. Uma releitura do papel da professora das séries iniciais no desenvolvimento e aprendizagem de ciências das crianças. Ensaio, V 8, n. 2, p.161-175, dez. 2006.

National Research Council (1996). National Science Education Standards. Washington, National Academy Press.

National Research Council (2000). Inquiry and the National Science Standards: A guide for teaching and learning. New York, National Academy Press.

National Science Foundation Inquiry (2005). Thoughts, Views, and Strategies for the K-5 Classroom, FOUNDATIONS: vol 2.

PAULA, H. A ciência escolar como instrumento para a compreensão da atividade científica. Tese (doutorado em educação). Universidade Federal de Minas Gerais. Belo Horizonte, 2004.

Peter Dow (2005). Why inquiry? A historical and philosophical commentary. In: National Science Foundation Inquiry: Thoughts, Views, and Strategies for the K-5 Classroom, FOUNDATIONS: vol 2.

Sandoval, W. A., \& Reiser, B. J. (2004). Explanation-driven inquiry: integrating conceptual and epistemic scaffolds for scientific inquiry. Science Education, 88. 345-372.

Schwab, J.J. (1960). What do scientists do? Behavioral Science, 5:1-27.

Schwab, J.J., (1962). The teaching of science as enquiry. In: J.J. Schwab \& P.F. Brandwein (eds.). The teaching of science, Cambridge: Harvard University Press, p. 3-103.

Schwab, J.J., (1962), The concept and structure of a discipline. Educational Record, 43, 197-205);

Schwab, J.J., Schwab (1964), The structure of natural sciences. In: G.W. Ford \& L. Pugno (eds.). The structure of knowledge and the curriculum. Chicago: Rand-McNally, p. 31-49. 